\title{
Enabling Social Responsibility through Inculcating Habits of Giving by Learning from Successful Non-profit Crowdfunding Campaigns
}

\author{
Fadhil A. Darwis and Sachi Arafat \\ Faculty of Computing and Information Technology, King Abdulaziz University, Jeddah, Saudi \\ Arabia \\ fdaewis@stu.kau.edu.sa
}

\begin{abstract}
Enabling social responsibility is a key goal of the Saudi 2030 vision and a strong factor for socioeconomic development of the Middle East and North Africa region in general. Our work explores how social responsibility can be enabled through inculcating habits of giving to nonprofit causes, using the KIVA crowdfunding platform, mobile technology and predictive analytics. We propose first that, based on prior research, the frequent involvement of a user in a successful campaign-by donating to it (even a small amount)-is an effective way to form the habit of giving/donation. Second, that in addition, involving the user in an optimal number of such campaigns in the shortest possible time is required for effective habit formation. As such, we investigate the factors that lead to nonprofit campaigns being funded quickly (within 12 days of origination at most), so that we can learn to effectively predict whether a new campaign would be successful within a short time. Campaigns predicted to be successful can be recommended to users through an effective interactive-design strategy within a suitable mobile application (as common to habit formation applications), and habits can thus be effectively formed. Our results show our current approach to be sufficiently successful in our required context, at predicting such campaigns, giving us hope that a full mobile solution that uses our analytics architecture would good strategy for habit formation.
\end{abstract}

Keywords: Habit formation, Predictive decision support, Crowdfunding, Non-Profit.

\section{Introduction}

Civic engagement is an important part of modern economies due to rising costs of traditional governance. A key part of this engagement is facilitating techniques for citizens to fund projects of interest to their own locality, or even in another region in order to fulfil their values. In the modern time, it is the crowdfunding technological platforms that are the main means of enabling this facilitation. Crowdfunding is a relatively recent phenomena where technology is used to solicit contributions from a mass of people towards a project that requires funding.
According to a report about the crowdfunding industry in 2015, fundraising event through crowdfunding platforms has reached $\$ 34$ billion with North America become the biggest region that contributes in the activity with $\$ 17,2$ billion in total ${ }^{[1]}$. Moreover, the latest statistic report stated that the current amount transaction value in crowdfunding platforms/websites has reached \$46.923,6 million by 2019 and it will surely increase by the end of the year ${ }^{[2]}$. People have different intentions for engaging in crowdfunding. In addition to providing charitable help to people in their locality, they may opt to support 
project that instead have particular monetary or other rewards for themselves.

We are interested in non-profit crowdfunding as we want to understand its potential in shaping cultures of civic engagement. In particular, we want to understand whether it could be possible to encourage the development the virtue (or moral-habit) of charity in the masses through repeated use of applications that incline people to donate small amounts of money to charitable projects over time, because habit is action that automatically done in daily routine which gotten by learn it and performed in certain amount of repetition especially in health aspect ${ }^{[3]}$. Thus, while the largest crowdfunding sites like Kickstarter do have non-profit campaigns (where the donator does not specifically benefit from the campaign), we focused our analysis on KIVA, the largest platform for non-profit and micro-loan based social projects that target to help people who are facing various difficulties in each circumstances of life ${ }^{[4]}$. There is much evidence that technology can be used for eliciting behavioral changes and in particular habit formation. The first example is an exploratory study about habit formation in dental flossing, the researchers' aim is to derive and determine each model that will affect people behavior in daily flossing activity. They included 50 people as the participant of the research with 24 of them get instructed to floss their teeth before brushing it and the rest of them instructed to do it after teeth brush. Every week, each of participant must report their flossing behavior in no more than two times (in baseline) by short message through their mobile phones and after a month, those activity is expected to be done automatically. To boost up the habit formation probability, all of participants has been given a kind of intervention in form of information about the advantages of flossing activity every day and it delivered through verbal and written way ${ }^{[5]}$. The next example in this section is a longitudinal study about exercise habit in the gym [6], purpose of this research is to investigate all requirements that have to be existed to form a habit of exercise, and how to predict behavior by using dual process approach. Our project investigates how this can be made use in the context of civicengagement through encouraging small donation-based crowdfunding of non-profit organizations.

This paper details one part of our current project that assesses whether non-profit campaign data (from KIVA) is useful for predicting which campaigns ought to be recommended to users such that their success is likely to inspire habits ${ }^{[7]}$ of giving in them. Our results contribute to understanding whether campaign success predictions are feasible, how they can be made possible, and how they may be used. In particular, section 2 further details our motivations, while section 3 elaborates on the particular methodology used to reach our results which are discussed in section 4. Finally, section 5 concludes this paper with some details about what requires to be done next.

\section{Motivation}

By doing this kind of civic engagement activities in daily routine, people who become donators will have contribution to their community, because helping one and another is a necessary thing especially in Islamic point of view and furthermore, it will also give economic impact which is important to every country. So that's why this research will become one small part of Saudi Arabia's 2030 Vision $^{1}$ which focused on enabling social

\footnotetext{
${ }^{1}$ Not only is the growth of the non-profit sector importance with respect to the 2030 vision but for contemporary sociopolitical growth and social change (that is the spirit of the 2030 vision) in the MENA region as a whole, see [25-26]
} 
responsibility ${ }^{[8]}$, particularly in persuading people to be more active and act to make their community better in the future. Moreover, charitable campaign will cultivate the feel of empathy and compassion to help one and another. It will also give them feel of relief and by doing it again and again, thus automatically shaping the habit of helping other people around. Digital technology, in particular, mobile technology, is recognized as an increasingly effective method of habit formation ${ }^{[9-16]}$.

The terms online crowdfunding or crowdsourcing start to emerge in 2007 and just based on the name, we can easily determine the purpose is to solicit contributions from other people in terms of financial or fund by targeting certain goal and rewards to the supporter at the end. People who take initial step to make campaign can find another people who are have the same interest through the platform and then normally exchanges their resources to find out about ideas. In the previous decade before crowdfunding are powered by computer and internet, people must engage and persuade another people in personal initiatives to get supported. As example, someone who have prototype of one product, must visit one person to another because they must clearly explain what the goal are and why their product must be produced in large amount. This is not efficient and at the end of the day, not all people who has been visited would have the same interest One of the first and biggest crowdfunding website is Kickstarter, this platform is famous for campaign that have creative contents. The site got recognized by Forbes magazine as one of the most popular crowdfunding website and varieties of creators like filmmakers, musicians, designers and any other creators got help and start their company based on campaign in this platform. Another wellknown crowdfunding website is KIVA, a little bit different with Kickstarter, this platform is focusing on social projects or campaigns and have main target to help people who are facing various difficulties in each circumstances of life ${ }^{[17-19]}$. There are at least four main aspects that can be influenced by the existence of crowdfunding system, including social validation, physiological state, mastery and role modelling ${ }^{[20]}$.

By donating through those platforms, people will get motivated to make and participate to fund a project through it, because it can gather everyone who have the same feeling and interest about one idea and then want to achieve the same goal at the end ${ }^{[21]}$. Thus, if there were tools and technologies that could facilitate this motivation, this would be a means for greater social good. Therefore, in order to help all donators in deciding which campaign to donate/support is another thing that must be delivered since it will be play important role in affecting or persuade more people to donate and it can be based on various themes or certain area of interest [22], to be able to do that kind of thing, a decision support tools have to be developed because it can be used to determine which campaign have bigger potential to be successfully funded and which campaign have less potential and cannot be continued ${ }^{[23]}$. In fact, there is research that conducted to help in giving predictions about each of new campaign's prospect, but they limit it just for internal use and not releasing it in form of supporting tools as needed ${ }^{[24]}$.

\section{Methodology}

The goal here is to create a system through which to inculcate behavioral changes in users with respect to the giving donations through inspiring a mass of individual acts of single instances of donations. The assumption here is that if a system is good at predicting successful campaigns, then the users that 
donate to them will be a part of that success, and this in turn create a emotionally-positive feedback loop that will encourage them to keep giving. A further assumption here is that, if they therefore engage in a sufficient number of giving-based behaviors over time, that this behavior will become a virtue (habituated moral character).

This project has two main parts, the first one is analysis of the KIVA data using clustering and classification techniques to find the campaigns that are most likely to succeed in the shortest period of time, and which therefore ought to be recommended for a user for their donation. Based on that, comes the second part which is developing mobile apps which based on android that have ability to display or provide the information that has been provided through the first part of this project. The apps will be called as Sarri' (based on Arabic word) which have ability not just displaying the result from analysis process, but it will able to give suggestion based on user's preferences so it can suggest the best and more suitable campaign to each of user and people who use it will be directly can contribute or become supporter of campaign by donating through crowdfunding platform. In the following, after detailing our idea about how repeated directed interactions can lead to behavioral change, we detail the completed first part of this project.

\section{Data Preparation and Modelling}

We completed the first part of the project and describe it in detail here. We analyzed several years (January 2014 - July 2017) of non-profit KIVA data which has been scraped and provided in build.kiva.org. This website is dedicated just for KIVA itself and provide the data that can be accessed by anyone. The dataset consists of approximately 671,000 data points which represents the amount of campaigns that already posted in KIVA's website and it have 20 variables in it, which can be seen in Table 1 below.

Table 1. Original dataset variables.

\begin{tabular}{|c|c|c|}
\hline No & Variable Name & Description \\
\hline 1 & ID & Loan ID \\
\hline 2 & $\begin{array}{l}\text { FUNDED } \\
\text { AMOUNT }\end{array}$ & $\begin{array}{l}\text { Amount of loan which has been } \\
\text { purchased by Kiva lenders }\end{array}$ \\
\hline 3 & $\begin{array}{l}\text { LOAN } \\
\text { AMOUNT }\end{array}$ & $\begin{array}{l}\text { Amount of the loan which has } \\
\text { been paid off }\end{array}$ \\
\hline 4 & ACTIVITY & $\begin{array}{l}\text { Activity for which loan is } \\
\text { requested }\end{array}$ \\
\hline 5 & SECTOR & $\begin{array}{l}\text { Sector for which loan is } \\
\text { requested }\end{array}$ \\
\hline 6 & USE & Purpose of loans to be used \\
\hline 7 & $\begin{array}{l}\text { COUNTRY } \\
\text { CODE }\end{array}$ & Country code \\
\hline 8 & COUNTRY & Country name \\
\hline 9 & REGION & Location / area of borrowers \\
\hline 10 & CURRENCY & Used currency for each loans \\
\hline 11 & PARTNER ID & $\begin{array}{l}\text { Field partner ID for local lending } \\
\text { institutions }\end{array}$ \\
\hline 12 & POSTED TIME & $\begin{array}{l}\text { Date when loan was posted on } \\
\text { Kiva }\end{array}$ \\
\hline 13 & $\begin{array}{l}\text { DISBURSED } \\
\text { TIME }\end{array}$ & $\begin{array}{l}\text { Date when loan disbursed on } \\
\text { Kiva }\end{array}$ \\
\hline 14 & FUNDED TIME & $\begin{array}{l}\text { Date when loan was fully funded } \\
\text { on Kiva }\end{array}$ \\
\hline 15 & $\begin{array}{l}\text { TERMS IN } \\
\text { MONTH }\end{array}$ & Duration of loans in month \\
\hline 16 & \begin{tabular}{|l|} 
LENDER \\
COUNT \\
\end{tabular} & Amount of lenders for each loan \\
\hline 17 & TAGS & $\begin{array}{l}\text { Tags for every loan projects in } \\
\text { Kiva }\end{array}$ \\
\hline 18 & $\begin{array}{l}\text { BORROWER } \\
\text { GENDERS }\end{array}$ & Gender of borrower \\
\hline 19 & $\begin{array}{l}\text { REPAYMENT } \\
\text { INTERVAL }\end{array}$ & $\begin{array}{l}\text { Type of payment interval of } \\
\text { borrower in Kiva }\end{array}$ \\
\hline 20 & DATE & $\begin{array}{l}\text { Date when loan project get } \\
\text { posted in Kiva }\end{array}$ \\
\hline
\end{tabular}

The campaigns' page in KIVA website are structured and it made easy to match with the dataset that has been derived from the scrapping website. Inside each of campaign's page, there are several attributes which include title of campaign, a picture, a progress bar for duration of campaign and the remaining amount of loans that needed, description of campaigns, length of loans, amount of donation and location with the sector of campaign (Fig. 1). 


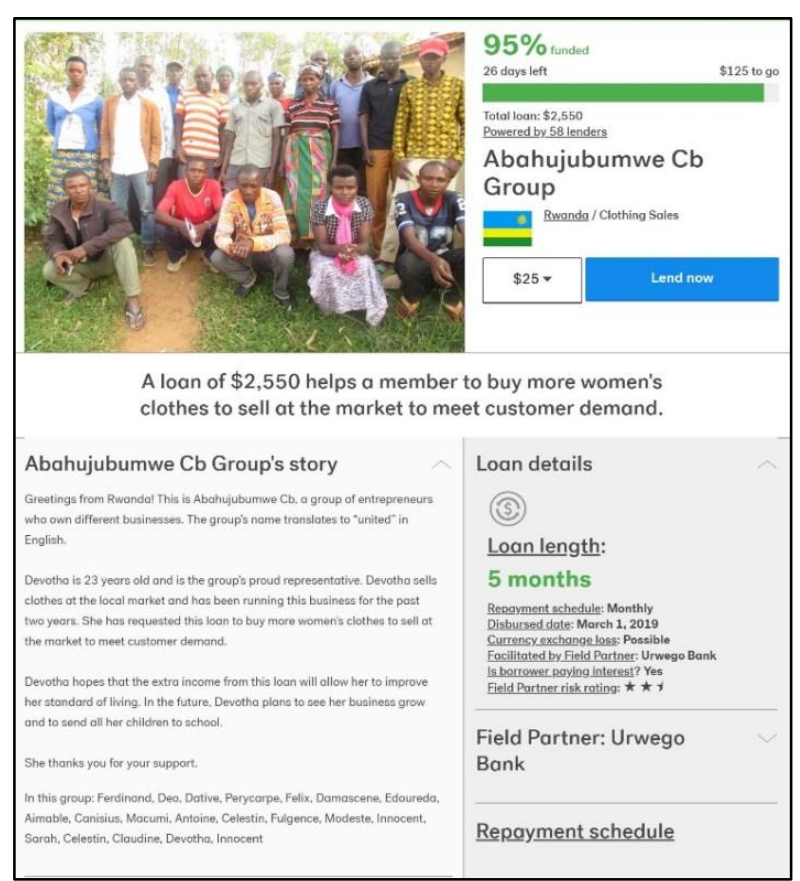

Fig. 1. Sample of campaign page in Kiva.

At the beginning phase of the analysis process we must clean all missing values from the dataset using one of native library that provided by $\mathrm{R}$. In this case we use na.omit to eliminate all entire rows which don't have complete values in it, so at the end we got 615,000 out of 671,000 datapoints that has been cleaned. Before discussing more details about data preparation steps, we want to convey that not all of the variables in the original dataset are used in this research, because the main purpose is to find out clustering in terms of time period for each campaign and later will be used in modelling process, so we only use some of variables which are related to time information in it. Once we get all rows that have complete values in it, the next step is to find out how much of campaigns which are succeeded, since we are going to do the analysis based on it later. To get it done, we decided to compare the 2 of variables which is loans amount and funded amount, then when the amount in those two variables are matched, then we make an additional variable to store the information (we put 1 for successful campaign and 0 for failed campaign) and this new variable called as end result. At the end of that process we have can see that most of the campaigns that has been posted through KIVA has been fully funded which is what we need in this research. But in other hand, we decided to make a new criterion of success for this research, in this case try to find out how long the duration for each of campaigns that has been successful until it gets fully funded. Because in psychology aspect of it, by giving campaigns that are fully funded in short period of time to the user, will give better encouragement for them to donate more frequently ${ }^{[5]}$. To achieve and produce that information, we continued to add more variables that based on existing variables which is posted time and funded time. In fact, those variables give the specific date and time of each campaign but since we just need the date to be used for another new variable, then we decided to eliminate the time part for the whole data. Then after that we put the result into new fields which is Posted time 2 and Funded time 2, then we make another additional variable that can show the specific amount of days by do simple reduction operation by using previous variables (Funded time 2 - Posted time 2) and put the result under duration variable. After looking at the overall variables/fields that we have including those new variables, we decided to use categorical analysis for this dataset. Then we use clustering to help us find how many proper amounts of classes based on duration variable that we need in case of suggesting the only fastest campaigns to the user for habit formation purposes. We applied the KMeans clustering algorithm by using NBClust library [26] to help us finding out the best featureclasses for later classification using naïve bayes. In particular, we used seven variations (100, 1000, 3000, 4200, 5000 and 10000) points as input to the clustering, and two different sets of parameters (input features), 
either 2 features (funded amount, and duration) or four (funded amount, terms in month, lender count, duration). The limited number of variables is due to a limitation in NBclust library, so it can only take maximum 10000 datapoints in one cycle of clustering with 2 variables in it. Furthermore, when we use 4 variables in one cycle of process the algorithm can only take approximately 4200 datapoints. The variation in these parameters was for the purpose of getting a stable result.

Upon cluster analysis we added an extra column Time Cluster to the data that split it according to its membership to the respective time-cluster/class: it indicates which campaign belong to which cluster based on time duration to be successfully funded. Since algorithm that we used in this research requires vectorized data, then after we completed all of necessary things as mentioned above, the final thing is we convert all of variables into vector format before we use fetch it into the prediction algorithm. All additional variables that has been produced in data preparation process are listed in Table 2.

Table 2. Additional variables.

\begin{tabular}{|l|l|}
\hline No & Variable Name \\
\hline 1 & POSTED TIME2 \\
\hline 2 & FUNDED TIME 2 \\
\hline 3 & END RESULT \\
\hline 4 & DURATION \\
\hline 5 & TIME CLUSTER \\
\hline
\end{tabular}

The next phase of this research is the main analysis process which will give us the proper prediction model that we need in order to fulfill the goal which is predict a new campaign's prospect whether it will be succeed or not, we also can derive information about what clusters of time the campaign will be placed and based on that, the proper/fast fully funded campaigns will be displayed to the user. To achieve the goal, we decided to use Naïve Bayes algorithm, since this is one of common and widely used modelling algorithm specifically for categorical data which matched our data condition. Then for the validation purposes, we decided to use 10 -fold cross validation and bootstrap methods of resampling in order to get the performance evaluation of the model that we have as the result of analysis process. There are 4 different variations of split ratio for each of those datapoints' amount in terms of training and testing set that included in the model which are produced by the Naïve Bayes algorithm. The percentage are, $20 \%$ training : $80 \%$ testing, $50 \%$ training : $50 \%$ testing, $70 \%$ training : $30 \%$ testing and $80 \%$ training : $20 \%$ testing. Besides that, we also use 7 different variations for the amount of datapoints (1000, 3000, 10000, 30000, 100000, 300000 and 615000). The reason behind those variations are to get stable results of prediction and at the same time to get prediction model that can be used for another set of data and modelling algorithm. Detailed explanation of how to determine time cluster in data preparation and the result of analysis of prediction model will be discussed in the next section.

\section{Results and Discussions}

The results that we got in cluster analysis using 2 and 4 different variables and seven variations of data points as input parameters is shown in Fig. 2-5 and Fig. 6-8. As the results from the elbow-test and other test in NBClust indicate, the most adequate number of clusters that are needed are 3: cluster 1 (with duration 05 days) with 178,497 campaigns, cluster 2 (with duration 6-21 days) with 281,105 campaigns and the last one is cluster 3 (22-maximum days) with 155,461 campaigns in it. So, based on that we can see that majority of campaigns are inside the range of cluster 1 and 2 .

For clustering, the graphs do not admit much difference, even after we increased the amounts of variables from 2 to 4 and used the same variations of data amounts. Thus, we 
infer that this data is best divided into 3 clusters. Upon using those clusters as our classes for classification, we found Naïve Bayes to have the following performance. The results below as shown in Fig. 2-8 are the averaged over split-ratio and repetition as the variation in them did not result in significant different in performance. As shown in those graphs, we used 3 different validation variations: Naïve Bayes only (Non-CV), 10fold Cross Validation (CV), and Bootstrap.

As stated before, there are no significant change between cluster 1 and cluster 2 in terms result of precision for prediction in our model here. It shown that the stability happened after we use 10,000 datapoints and keep that way up until it reached 30,000 regardless of those 3 different validation variations that has been used. There are so much fluctuated or unstable result before 10,000 mark and then the precision keeps falling down when the amount of datapoints increased for more than 30,000 mark as shown in Fig. 9 - 10.

In terms of recall, we found out some variations in the result between cluster 1 as shown in Fig. 11 and cluster 2 in Fig. 12. But regarding of 3 different validations variation that has been used, again there are no significant change in each of the clusters. Here we can see that it can reached stability when the amount of datapoints that been used is between 10,000 and 30,000. Moreover, for cluster 1 when the amount is raised up more than 30,000 the result of recall is going down. Meanwhile for cluster 2, once we increased the amount of data, then the recall become slightly better if compared between those 3 variations as shown below.
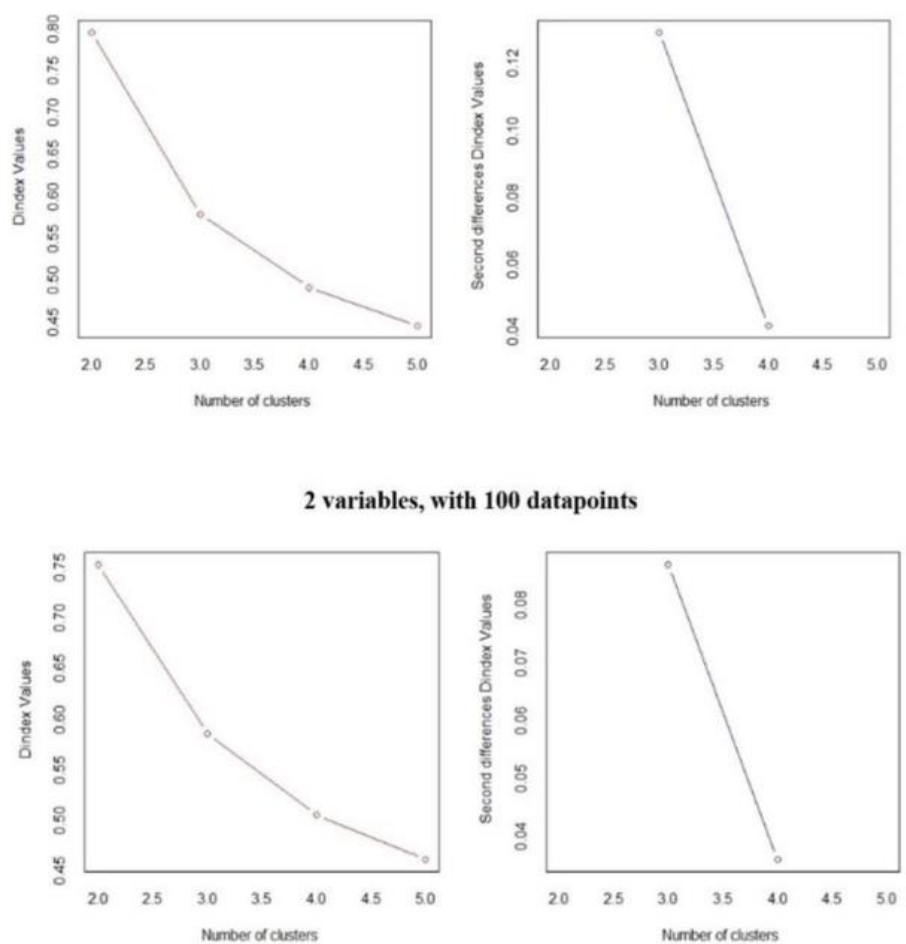

2 variables, with 1000 datapoints

Fig. 2. Clustering result using NBClust with 2 Variables (100 \& 1000 datapoints). 

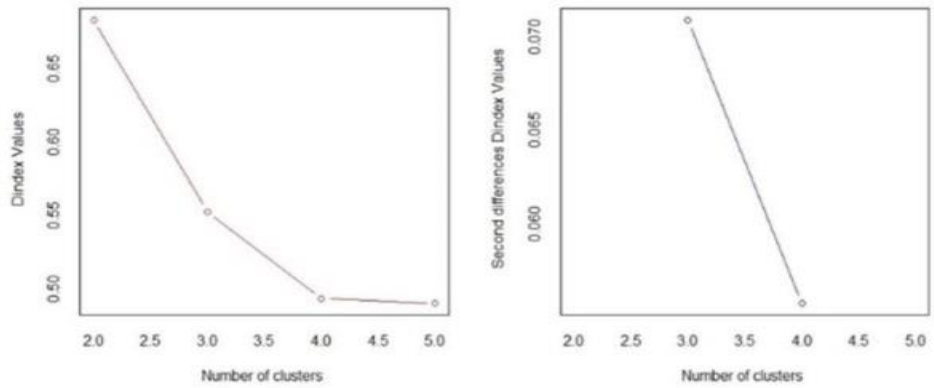

2 variables, with 3000 datapoints
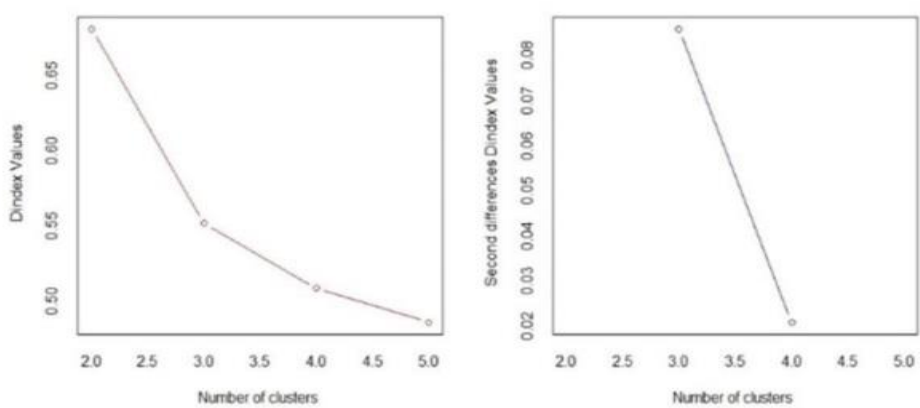

2 variables, with 4000 datapoints

Fig. 3. Clustering result using NBClust with 2 Variables (3000 \& 4000 datapoints).
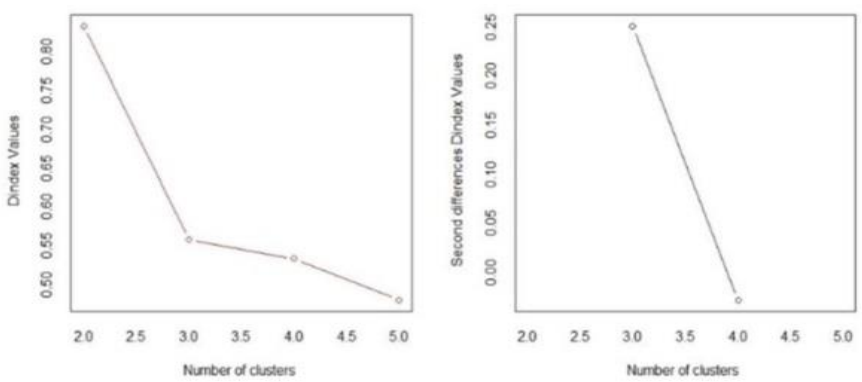

2 variables, with 4200 datapoints
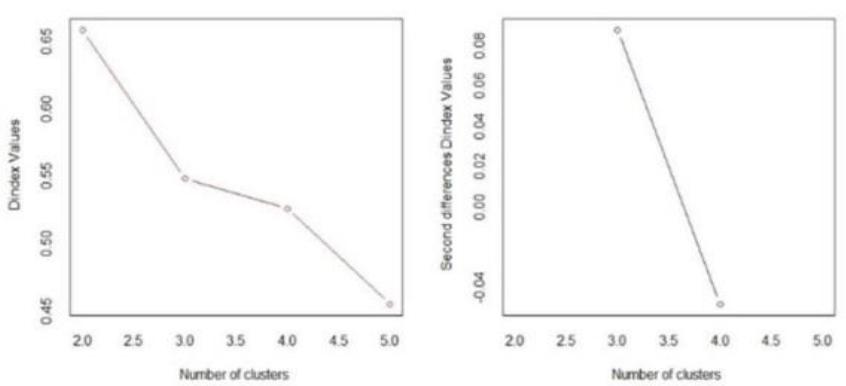

2 variables, with 5000 datapoints

Fig. 4. Clustering result using NBClust with 2 Variables (4200 \& 5000 datapoints). 

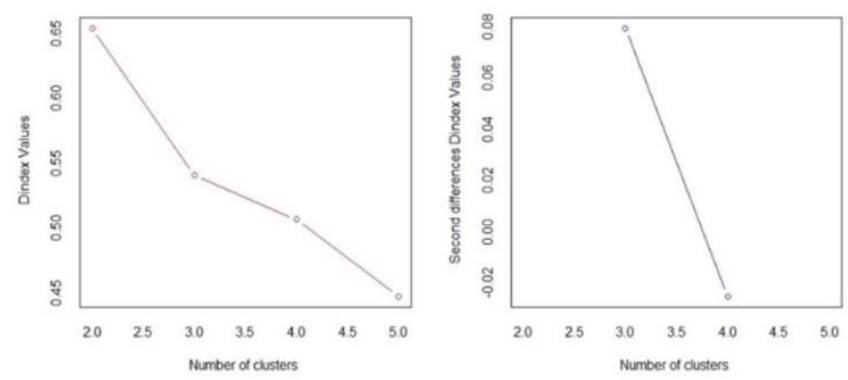

2 variables, with 10000 datapoints

Fig. 5. Clustering result using NBClust with 2 Variables (10000 datapoints).
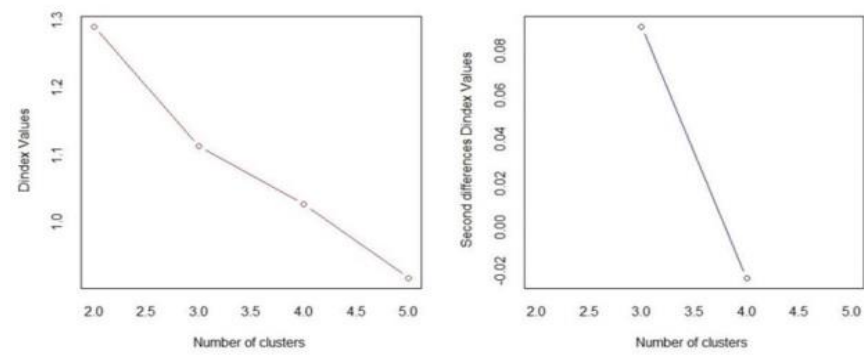

4 variables, with 100 datapoints
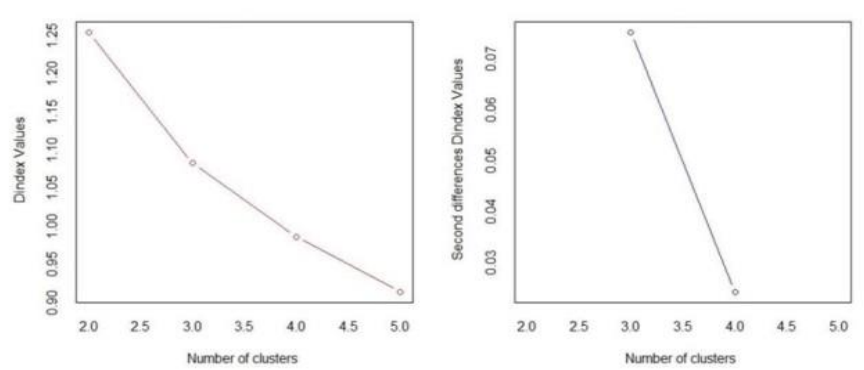

4 variables, with 1000 datapoints

Fig. 6. Clustering result using NBClust with 4 Variables (100 \& 1000 datapoints).
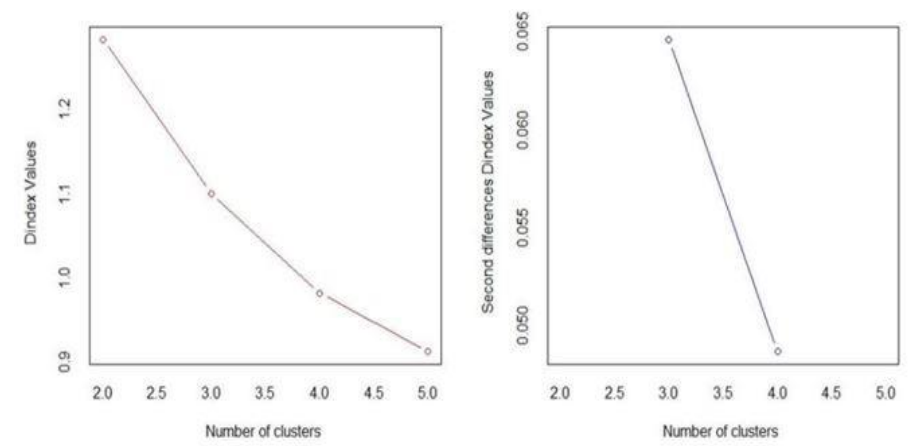

4 variables, with 3000 datapoints

Fig. 7. Clustering result using NBClust with 4 Variables (3000 datapoints). 

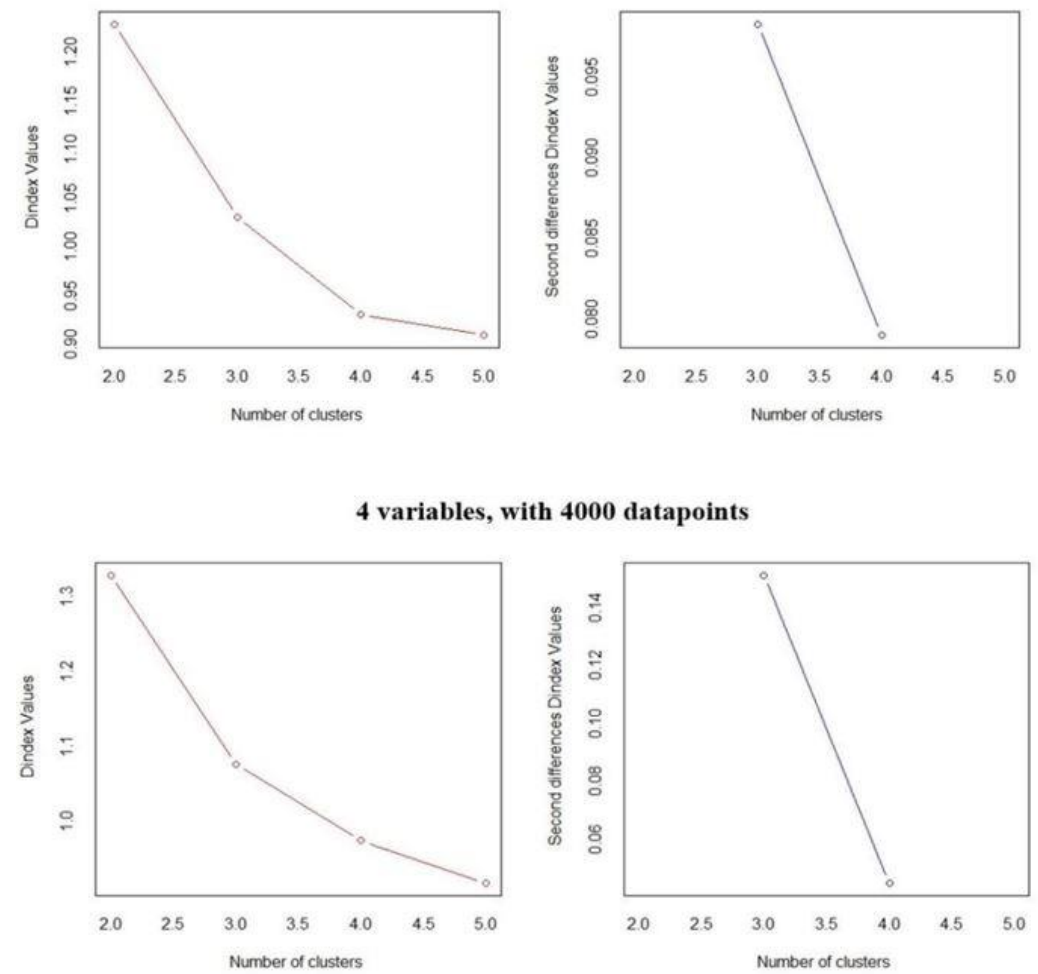

4 variables, with 4200 datapoints

Fig. 8. Clustering result using NBClust with 4 Variables (4000 \& 4200 datapoints).

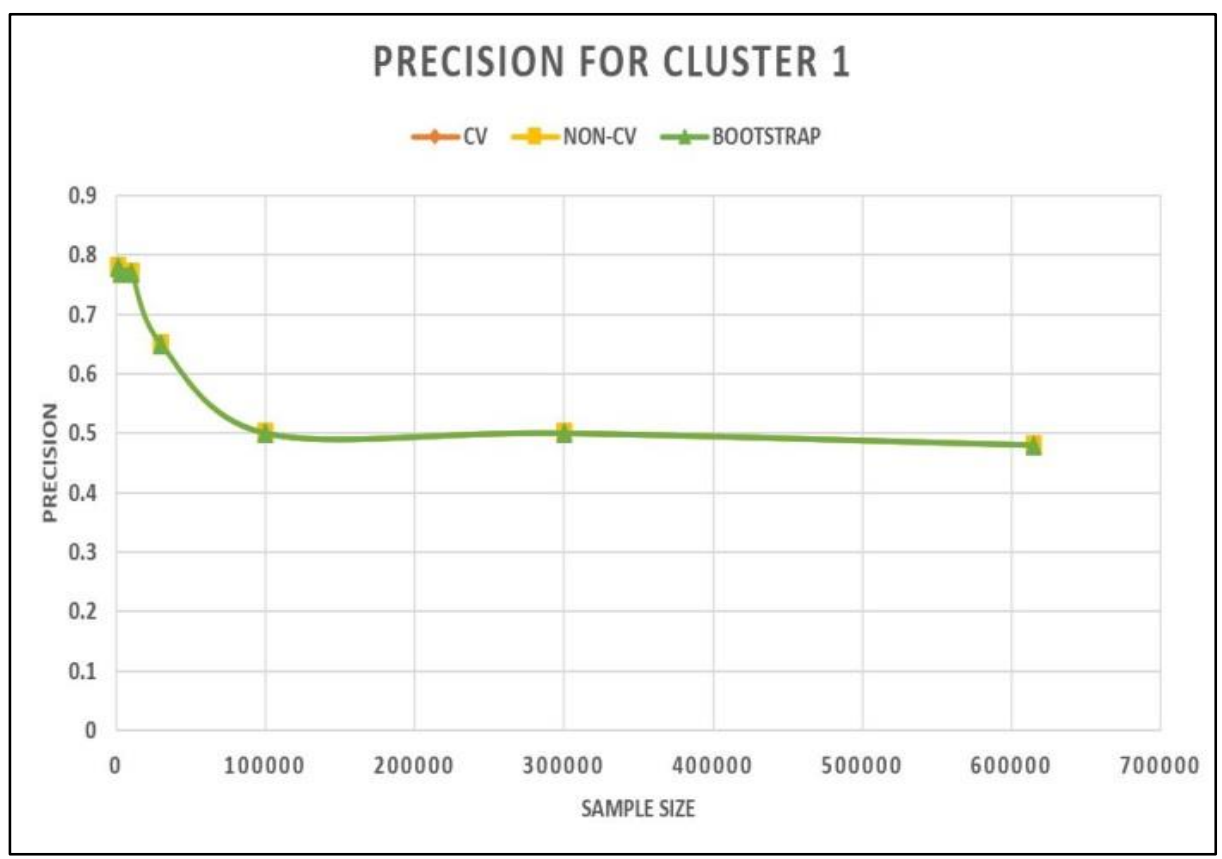

Fig. 9. Scatterplot of CV, Non-CV and Bootstrap of Precision for Cluster 1. 


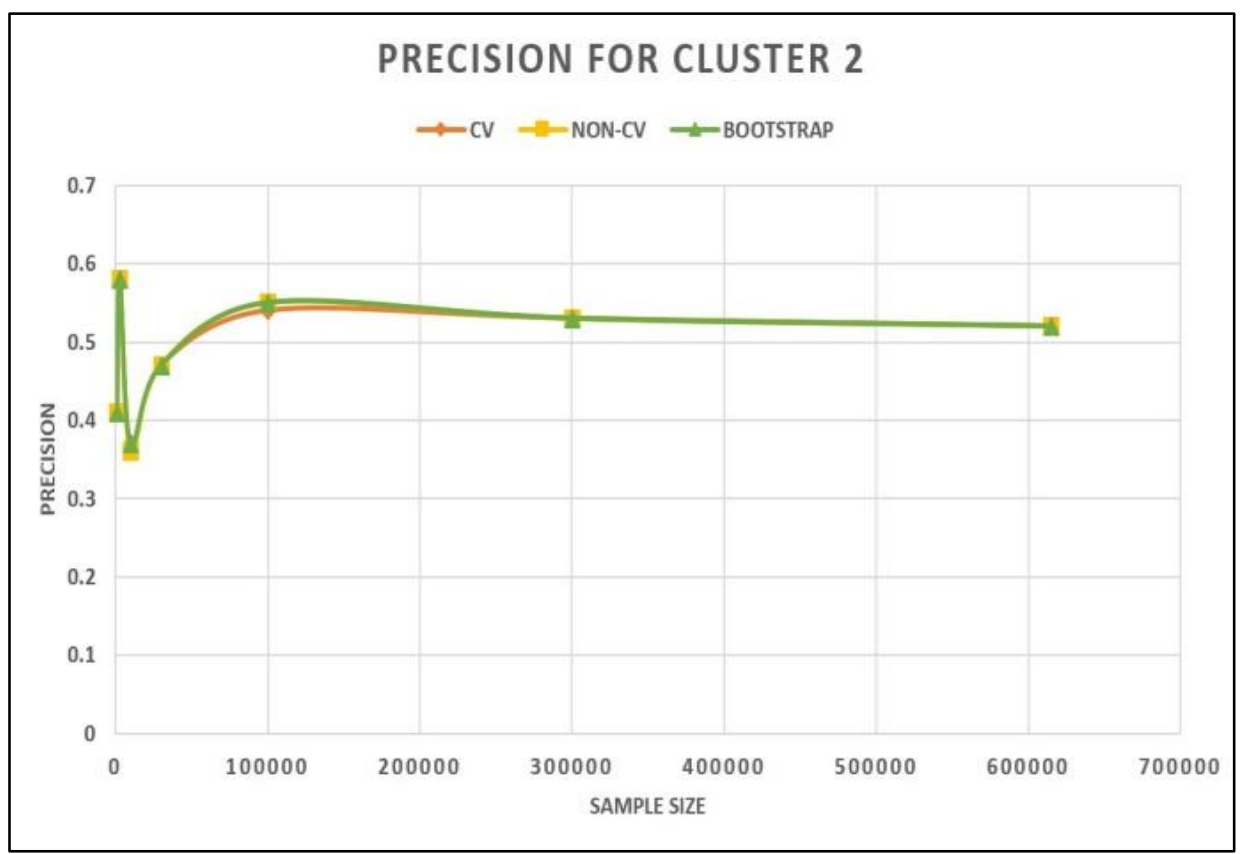

Fig. 10. Scatterplot of CV, Non-CV and Bootstrap of Precision for Cluster 2.

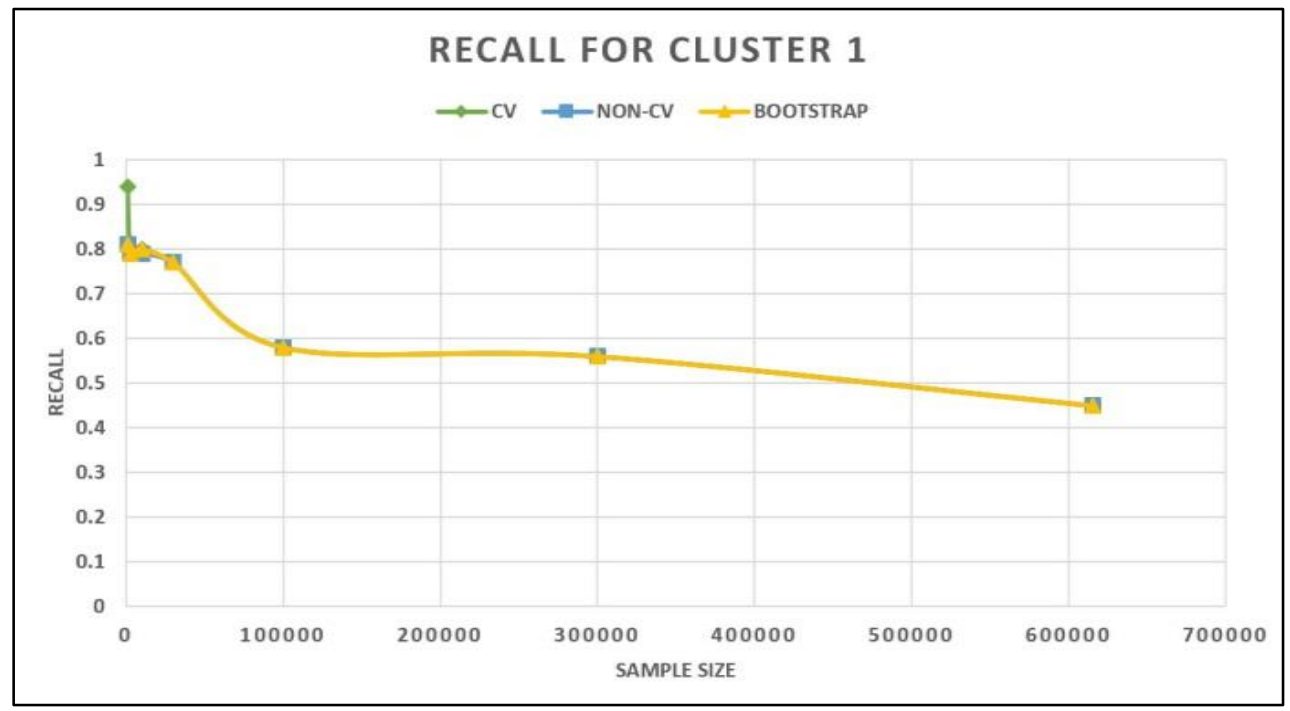

Fig. 11. Scatterplot of CV, Non-CV and Bootstrap of Recall for Cluster 1. 


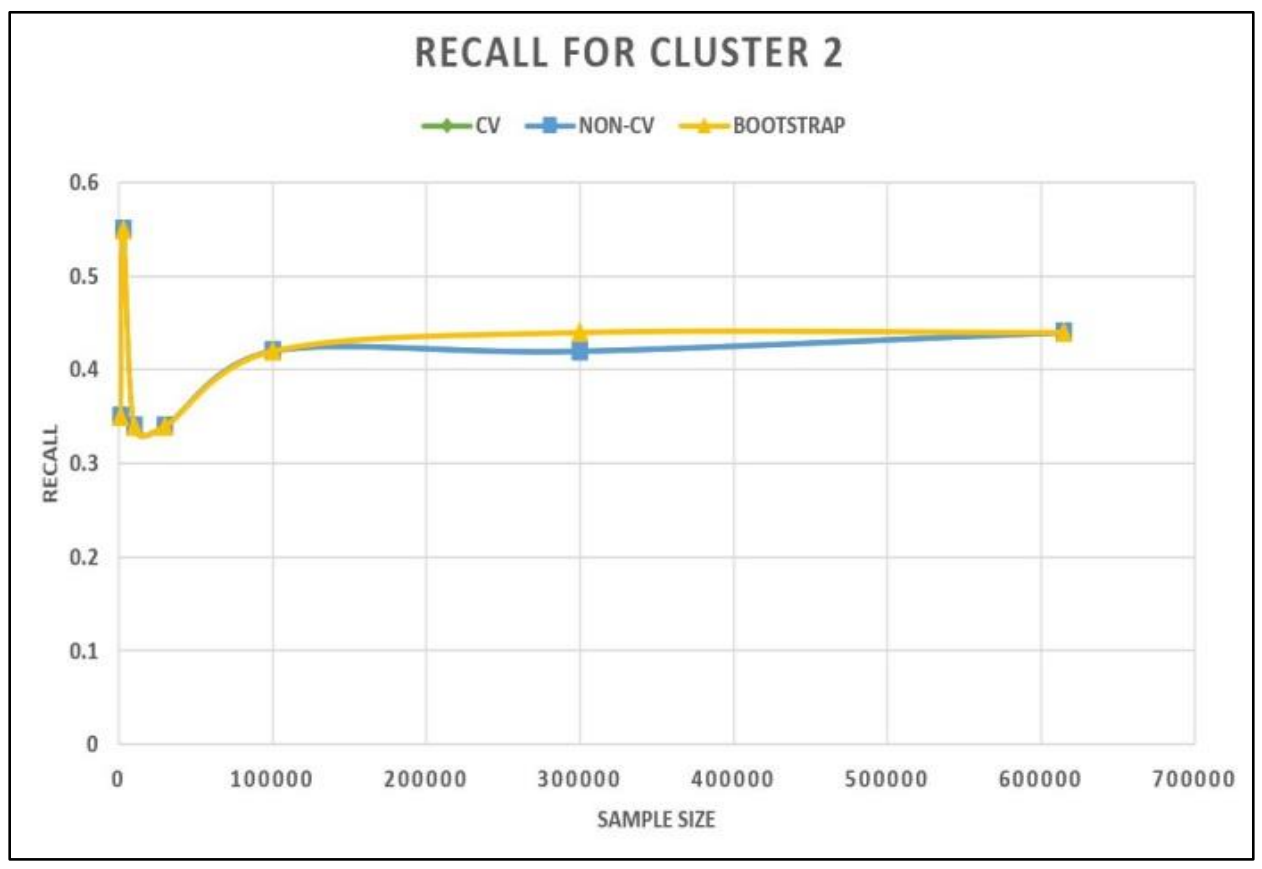

Fig. 12. Scatterplot of CV, Non-CV and Bootstrap of Recall for Cluster 2.

In most of the cases that we had during this research, we found out that the best and stable prediction result can be achieved when the amount of datapoints that become the parameter have to be between 10,000 and 30,000 . We also found out that there are some issues with the stability when the amount of datapoints are below 10,000 and once the datapoints that inputted to the model that we have are above 30,000, then the result of precision and recall are generally goes down or doesn't changed much.

In advance, there are some result that shown us slightly better in terms of recall, but we need to include more amount of datapoints into the validation process. A single KIVA campaign (let alone the entire set of active campaigns) can change several times a day or even more for popular campaigns. This means, we can use those brand-new data and fetch them to our model to see if those new campaigns can be succeeded or not and how long it will take to be fully funded. But it doesn't mean that we can take or utilize up until hundred thousand of datapoints to produce good enough prediction because based on what we found during this research, the best amount of data point in our case is between 10,000 and 30,000 mark. So, it will be easier to get new data in those amounts and it can be achieved in less than a week. At the end, our prediction model can be more versatile to the current trend of campaigns because it used relatively new data. We also found out that our prediction model can achieve up until $50 \%$ precision and recall, so we can make sure that each of new campaigns that created in the website will have at least $50 \%$ success rate if it can fulfill the success criteria that has been set and applied to the model that we have.

Overall, our results show that KIVA's nonprofit campaigns cluster around three groups, each with a distinct time signature. There are the quickly funded campaigns (0-5 days), the medium-duration campaigns (6-21 days) and the long campaigns (>21 days). This made clear to us that in order to enable habit 
formation, especially for the younger generation who expect immediate responses to their (donation) projects, we have to be able to predict successful campaigns that are quickly funded (0-5 days). We do expect the mediumduration campaigns to still be effective in forming habits, but we not expect the long campaigns would be much use for us at this stage. As a result, we focused on optimizing predictions of quick and medium-term success, cluster 1 and cluster 2 above. Our Naïve Bayes classification model performed best (in that it had high precision and recall while being stable), with 10k-30k data points, for both these clusters. However, precision/recall results were around the $50 \%$ mark.

Precision is important as suggesting too many campaigns that do not go on to be successful would have a negative effect on habit formation. Whether $50 \%$ precision is a good enough result or not depends on how the mobile interactive strategy would employ predictions with such a performance. We do not expect a user's habit formation to be too negatively affected by only being part of a successful project $50 \%$ of the time, especially when (as is the plan) they are encouraged to donate small amounts. This is certainly what is expected in other financial investments such as short-term trades in the stock market which are high-risk yet high return. In our case, at 50\% the 'risk' of being part of a failed project are not that high, and a failed project does not imply any financial loss, and yet a successful project (which is equally likely) is potentially 'high return' in an ethical sense due to (a) the tangible social good it would effect and also due to (b) the habit it would help to inculcate in the user (which would be an even higher return, in the ethical sense). As a result, we think our results show promise that the KIVA dataset and our overall methodology would be a good candidate-setup for an effective, mobile-app based habit-formation system.

\section{Conclusion and Future Work}

Our results show that the KIVA dataset and our overall methodology offer a promising way to predict successful nonprofit campaigns that can be suggested to users in order to develop their habit of donating small amounts of money to charitable causes. Thus, we have confidence that, the frequent involvement of a user in a successful campaign-by donating to it (even a small amount)-will be an effective way to form the habit of giving/donation. Furthermore, this gives us hope that a full mobile solution that uses our analytics architecture would good strategy for habit formation.

To this end, the immediate next task for future work would be to investigate whether (a) there are any other relevant sub-clusters (e.g. pertaining to campaigns funded in $0-2$ days or 2-3 days) not detected by our methods that would nevertheless be better predicted by our current classification model and whether (b) other classification models (other Bayesian classifiers, SVM, deep-learning models, random-forest etc.) perform better for our current clusters or the other relevant clusters (generated as a result of (a)). Once we are satisfied that we have the most relevant set of clusters and an upper bound for classifying into them, then could start developing interaction strategies (including an interface) for the mobile frontend (app). For example, if the upper bound of precision remains around $50 \%$, then both (i) interface elements and (ii) automated donation re-distribution strategies, would have to be designed to mitigate the negative psychological effect of 'failed campaigns' on habit formation, and to amplify the effect of successful campaigns; this is since both are equally likely. An example of (ii) could be to not even visually indicate 'a failed campaign', but instead show it as a 'migrated campaign'-meaning that the 'user's project of donating to that campaign' has not 
failed or lost anything, but instead the system has simply moved the donations to another 'better performing' campaign. That is, to effect a strategy that delays the delivery of 'bad news' (of a failed campaign) and instead gives good news (hiding the bad news) when the money for the failed campaign funds a successful campaign. Similarly, the specific prediction results will determine the interactive strategies.

In addition, we would have to evaluate actual habit formation events through extensive user testing once the mobile application has been developed, to see which interactive strategies are most conducive to habit formation. We are excited by the potential applications of our project in real-life habit formation settings especially when deployed to massive numbers of users.

\section{References}

[1] http://crowdexpert.com/crowdfunding-industry-statistics/

[2] https://psychology.iresearchnet.com/socialpsychology/control/feedback-loop/

[3] Gardner, Benjamin, Habit as automaticity, not frequency, European Health Psychologist, 14: 32-36, 2012.

[4] Flannery, Matt. "Kiva and the birth of person-to-person microfinance." Innovations: Technology, Governance, Globalization 2.1-2 (2007): 31-56.

[5] Judah, Gaby and Gardner, Benjamin and Aunger, Robert, Forming a flossing habit : an an exploratory study of the psychological determinants of habit formation, British Journal of Health psychology, 18: 338-353, 2013.

[6] Kaushal, Navin and Rhodes, Ryan E., Exercise habit formation in new gym members: A longitudinal study, Journal of Behavioral Medicine, 38: 652-663, 2015.

[7] Carden, Lucas and Wood, Wendy, Habit formation and change. Current Opinion in Behavioral Sciences, 20: 117-122, 2018.

[8] KSA Vision 2030: Strategic Objectives and Vision Realization Programs, https://www.vision2030.gov.sa/ download/file/fid/1319

[9] Stawarz, Katarzyna, Cox, Anna L. and Blandford, Ann, 2015. Beyond Self-Tracking and Reminders: Designing Smartphone Apps That Support Habit Formation. In: Proceedings of the 33rd Annual ACM Conference on Human Factors in Computing Systems (CHI '15). ACM, New York, NY, USA, 2653-2662.

[10] Carden, Lucas and Wood, Wendy, Habit formation and change. Current Opinion in Behavioral Sciences, 20: 117-122, 2018.

[11] Pinder, Charlie, Vermeulen, Jo, Cowan, Benjamin R. and Beale, Russell, 2018. Digital Behaviour Change Interventions to Break and Form Habits. ACM Trans. Comput.-Hum. Interact. 25(3) Article 15 (June 2018),

[12] Lally, P., van Jaarsveld, C. H., Potts, H. W. and Wardle, J., 2010, How are habits formed: Modelling habit formation in the real world. Eur. J. Soc. Psychol., 40: 998-1009.

[13] Renfree, Ian, Harrison, Daniel, Marshall, Paul, Stawarz, Katarzyna and Cox, Anna, 2016. Don't Kick the Habit: The Role of Dependency in Habit Formation Apps. In Proceedings of the 2016 CHI Conference Extended Abstracts on Human Factors in Computing Systems (CHI EA '16). ACM, New York, NY, USA.

[14] Rooksby, John, Rost, Mattias, Morrison, Alistair and Chalmers, Matthew Chalmers, 2014. Personal tracking as lived informatics. In Proceedings of the 32nd annual ACM conference on Human factors in computing systems (CHI '14). ACM, New York, NY, USA, 1163-1172.

[15] Hollis, Victoria, Konrad, Artie and Whittaker, Steve, 2015. Change of Heart: Emotion Tracking to Promote Behavior Change. In Proceedings of the 33rd Annual ACM Conference on Human Factors in Computing Systems (CHI '15). ACM, New York, NY, USA, 26432652.

[16] Hsiao, Chun-Hua, Chang, Jung-Jung and Tang, KaiYu, Exploring the influential factors in continuance usage of mobile social Apps: Satisfaction, habit, and customer value perspectives, Telematics and Informatics, 33(2), 2016.

[17] Flannery, Matt. "Kiva and the birth of person-toperson microfinance." Innovations: Technology, Governance, Globalization, 2.1-2 (2007): 31-56.

[18] Aitamurto, Tanja. "The new role of nonprofit organizations: From middleman to a platform organization." National Civic Review, 100.1 (2011): 40-41.

[19] Song, Aejin, Lee, Hong-in, Ko, Minsam and Lee, Uichin, 2015. Every Little Helps: Understanding Donor Behavior in a Crowdfunding Platform for Non-profits. In Proceedings of the 33rd Annual ACM Conference Extended Abstracts on Human Factors in Computing Systems (CHI EA '15). ACM, New York, NY, USA, 1103-1108.

[20] https://psychology.iresearchnet.com/socialpsychology/control/feedback-loop/

[21] Carvajal, M., Garcia-Avilos, J. A. and Gonzalez, J. L. Crowdfunding and nonprofit media: The emergence of new models for public interest journalism, Journalism Practice, 6(5-6): 638 647, 2012.

[22] Chiu, C.-M. Liang, T.-P. and Turban, E., What can crowdsourcing do for decision support? Decision Support Systems, 65: 40 49, 2014.

[23] Gerber, E. M., Hui, J. S. and Kuo, P.-Y., Crowdfunding: Why people are motivated to post and 
fund projects on crowdfunding platforms, in Proceedings of the International Workshop on Design, Influence, and Social Technologies: Techniques, Impacts and Ethics, vol. 2, 2012, p. 11.

[24] Greenberg, M. D., Pardo, B., Hariharan, K. and Gerber, E., Crowdfunding support tools: predicting success \& failure, in CHI'13 Extended Abstracts on Human Factors in Computing Systems. ACM, 2013, pp.
18151820.

[25] Ibrahim, Barbara and Sherif, Dina H. (eds). From Charity to Social Change: Trends in Arab Philanthropy, pp. 65-86. The American University in Cairo Press: New York

[26] Montagu, Caroline. "Civil society and the voluntary sector in Saudi Arabia." The Middle East Journal, 64(1): 67-83 (2010). 
تمكين المسؤولية الاجتماعية من خلال غرس عادات العطاء عن طريق التعلم من حملات التمويل الجماعي غير الربحية فاضل أغستا دروي و ساتثي عرفات

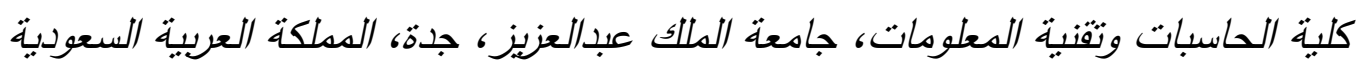
fdaewis@stu.kau.edu.sa

المستخلص. يعد تمكين المسؤولية الاجتماعية هدفًا رئيسيًا لروئة المملكة العربية السعودية

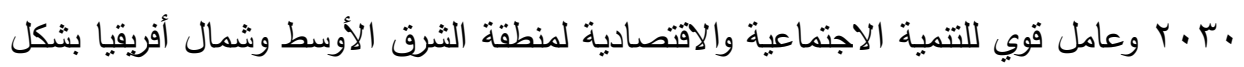

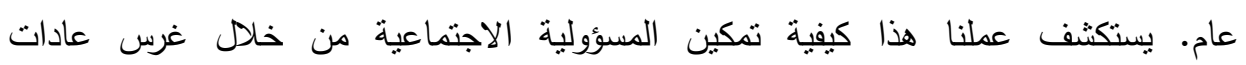

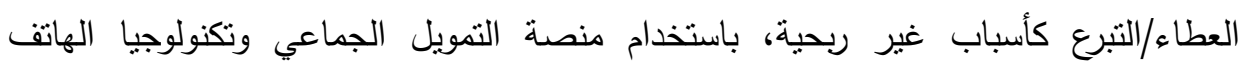

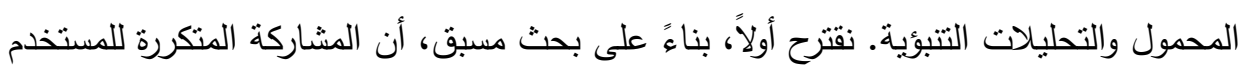

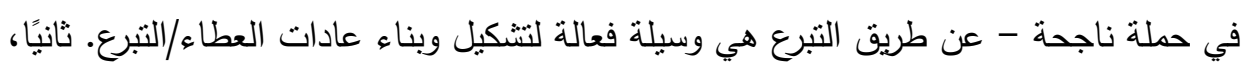

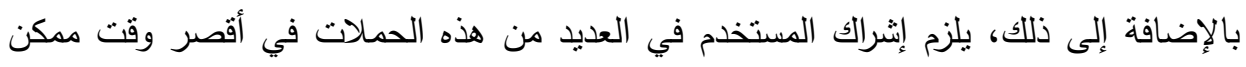

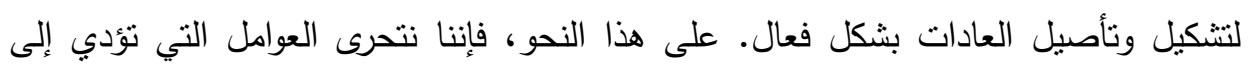

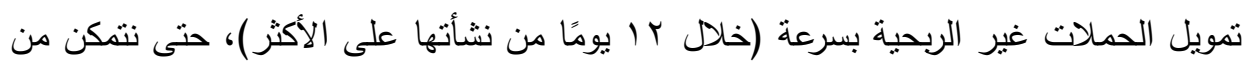

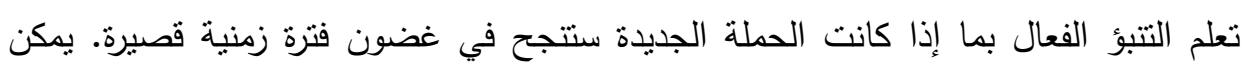

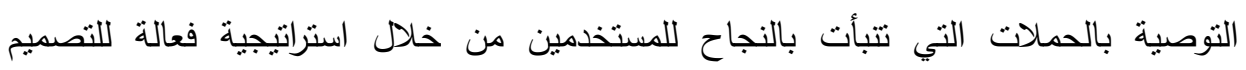

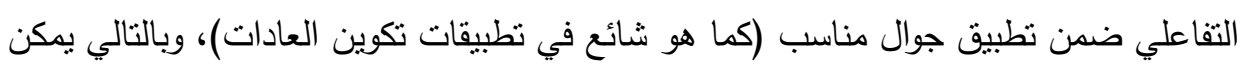

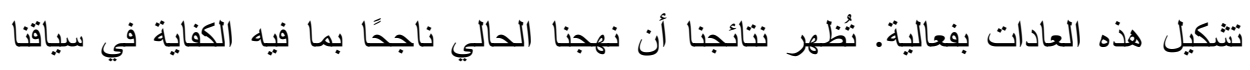

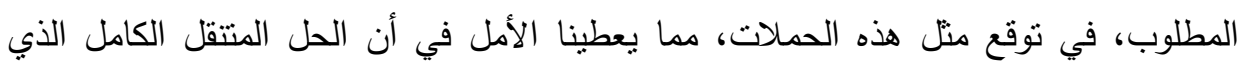

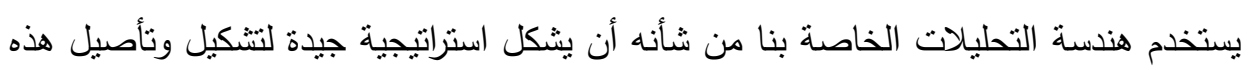

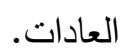

الكلمات الدقتاحية: تشكيل العادة، دعم القرار التتبؤي، التمويل الجماعي، غير ربحية. 